\title{
Role of Defects and Metal Coordination on Adsorption of Acid Gases in MOFs and Metal Oxides: An In Situ IR Spectroscopic Study
}

\author{
William P. Mounfield, $\mathrm{III}^{\mathrm{a}}$, Uma Tumuluri ${ }^{\mathrm{b}}$, Yang Jiao ${ }^{\mathrm{a}}$, Meijun $\mathrm{Li}^{\mathrm{c}}$, Sheng Dai ${ }^{\mathrm{b}, \mathrm{c}}, \mathrm{Zili} \mathrm{Wu}^{\mathrm{b}}$, and Krista S. \\ Walton ${ }^{\mathrm{a} *}$
}

a. School of Chemical and Biomolecular Engineering, Georgia Institute of Technology, Atlanta, Georgia 30332, United States

b. Chemical Sciences Division, Oak Ridge National Laboratory, Oak Ridge, Tennessee 37831, United States

c. Department of Chemistry, University of Tennessee, Knoxville, TN 37996, United States.

\section{Corresponding Author}

*Email: krista.walton@ chbe.gatech.edu Phone: 404.894.5254 Fax: 404.894.2866 Website:

http://walton.chbe.gatech.edu 


\section{ABSTRACT}

Metal-organic frameworks (MOFs) often display promising performance in ideal, one- or two-component systems; however, industrial adsorption and catalytic applications are almost always in the presence of acid gases that degrade the adsorbent or catalyst. Therefore, it is necessary to understand the interaction of acid gases with MOFs to drive future material design. Acid gas adsorption has been widely investigated on metal oxides, while few fundamental studies exist for MOFs. Therefore, MOF-derived oxides were prepared to give insight into adsorbed species on MOFs by connecting to the understanding that exists for adsorbed species on metal oxides. These MOF-derived oxides retain the overall morphology of the parent MOF, allowing direct comparison of the effect of morphology and the metal coordination environment on adsorbed species and acid gas stability of MOF, MOF-derived oxide, and traditionally synthesized metal oxide. A cerium-based MOF with open-metal sites, CeBTC, and the Ti-based MIL-125 were chosen to prepare MOF-derived oxides. IR studies show that adsorbed species during $\mathrm{SO}_{2}$ and $\mathrm{CO}_{2}$ adsorption on the MOF materials could be directly correlated to species observed on the MOF-derived and traditional oxides. In addition, the adsorbed species on the MOF-derived oxides differed from traditional oxides due to their different morphology and retained porosity. SEM and TEM images taken before and after $\mathrm{CO}_{2} / \mathrm{SO}_{2}$ adsorption experiments revealed degradation of all materials giving visual insight into the degradation mechanism after acid gas exposure. This study advances the understanding of acid gas adsorption on MOFs by correlation of adsorbed species with MOFderived and traditional metal oxides.

\section{KEYWORDS}

Metal-organic framework; ceria; titania; acid gas; MOF derived-oxide 


\section{INTRODUCTION}

Developing gas adsorption systems and catalytic applications for a wide range of industries has garnered much research attention in the field of porous materials.[1-9] Often, materials that are designed with promising capabilities for applications such as $\mathrm{CO}_{2}$ capture are unable to retain their performance in the presence of harsh acid gases that exist in many industrial applications.[10] To advance the development of industrially viable porous materials, a better understanding of the effects of these acid gases is required. Metal-organic frameworks (MOFs) have emerged as a promising class of materials for acid gas separations and catalysis. $[5,8$, $11,12]$ MOFs are characterized by metal clusters and organic linkers, large surface areas, and tunable chemical properties that make them excellent candidates for these applications. Recent work has also identified MOFs as excellent templates for producing MOF-derived unique, porous, structured metal oxides[13-18] that may offer improved acid gas separation and catalytic properties in comparison to their MOF or traditionally synthesized oxide (oxide) counterparts. Furthermore, these MOF-derived oxides can be used to study adsorbed species on MOFs by creating a bridge to the fundamental understanding of adsorbed species on metal oxides, which have been widely studied using IR[19-25], Raman[26, 27], and TPD[28] techniques. $\mathrm{CeO}_{2}$, for example, is widely used as a catalyst in the automotive industry,[29-32] and several studies have investigated the reduction in catalytic performance $\mathrm{CeO}_{2}$-based catalysts can suffer upon exposure to even low concentrations of $\mathrm{SO}_{2}$ present in exhaust gases.[33-37] $\mathrm{TiO}_{2}$ is also widely used in catalysis[38-40] and photocatalysis,[41] and the effect of exposure to various acid gases has been studied.[42-44] In conjunction with these studies, a MOF-derived $\mathrm{CeO}_{2}$ or $\mathrm{TiO}_{2}$ will allow the investigation of adsorbed species and effects of acid gas exposure with those observed for a parent cerium or titanium-based MOF. Therefore, these fundamental studies on metal oxides serve as an excellent basis for investigating the effect of acid gases on MOFs using MOF-derived oxides.

In this work, adsorption of acid gases, including $\mathrm{CO}_{2}$ and $\mathrm{SO}_{2}$, on several classes of materials was investigated using in situ IR spectroscopy coupled with mass spectrometric techniques. Adsorbed species were examined for each MOF-derived oxide and compared with an oxide as well as the parent MOF to gain insight into the similarities in these species across morphologies and coordination environments. Two sets of samples were 
chosen for comparison, a cerium series: $\mathrm{CeBTC}$, a cerium-based $\mathrm{MOF}, \mathrm{CeO}_{2}$-d derived from $\mathrm{CeBTC}$, and $\mathrm{CeO}_{2}$ wires, prepared and studied in previous studies,[45] and a titanium series: MIL-125, a titanium-based MOF that has shown promising acid gas removal properties, [46, 47] $\mathrm{TiO}_{2}-\mathrm{d}$ derived from MIL-125, and a bulk mixedphase $\mathrm{TiO}_{2}$. In addition to IR spectroscopic studies, the effect of acid gas exposure was also explored through SEM and TEM imaging before and after acid gas exposure, as well as structure analysis via XRD before and after in situ measurements. Water adsorption experiments were coupled with SEM and TEM imaging to investigate material stability and the similarity of the degradation mechanism during water and acid gas exposure. It is expected that exposure to $\mathrm{SO}_{2}$ would result in a decrease in the intensity/amount of adsorbed $\mathrm{CO}_{2}$ species for all samples and also the nature of adsorbed species for the MOF-derived oxide samples due to retention of $\mathrm{SO}_{2}$ species at potential adsorption sites and the degradation and loss of those sites. In addition, the visual degradation observed with SEM and TEM for MOF and MOF-derived oxide samples after exposure to $\mathrm{SO}_{2}$ or $\mathrm{H}_{2} \mathrm{O}$ gave insight into the degradation mechanism of these samples.

\section{EXPERIMENTAL}

Synthesis of CeBTC. The synthesis of CeBTC was performed using a similar procedure to that reported previously by $\mathrm{Mu}$, et al.[48] $\mathrm{Ce}\left(\mathrm{NO}_{3}\right)_{3} \cdot 6 \mathrm{H}_{2} \mathrm{O}(9.6 \mathrm{mmol})$ and 1,3,5 benzene tricarboxylic acid (BTC) (8 mmol) were added to $30 \mathrm{~mL}$ of $n, n$-dimethylformamide $(\mathrm{DMF})$ in a $60 \mathrm{~mL}$ scintillation vial. The vials were heated in an isothermal oven at $120{ }^{\circ} \mathrm{C}$ for 24 hours. The resultant beige product was rinsed with DMF three times followed by one methanol wash.

Synthesis of MIL-125. The synthesis of MIL-125 was performed by adding benzene dicarboxylic acid (BDC) $(2.75 \mathrm{mmol})$ to a mixture of DMF $(6.5 \mathrm{~mL})$ and methanol $(6.5 \mathrm{~mL})$. Acetic acid $(22.5 \mathrm{mmol}, 1.4 \mathrm{~mL})$ was added to the mixture before the addition of titanium isopropoxide $(0.75 \mathrm{mmol}, 0.22 \mathrm{~mL})$ to prevent the titanium precursor from hydrolyzing when added to the solution. The solution was placed in a $60 \mathrm{~mL}$ scintillation vial and heated in an isothermal oven at $110{ }^{\circ} \mathrm{C}$ for 24 hours. The resultant white product was rinsed with DMF three times followed by methanol one time. 
Synthesis of MOF-derived oxides. Porous anatase $\mathrm{TiO}_{2}$ and porous $\mathrm{CeO}_{2}$ were prepared using the method described in a previous study for preparation of porous $\mathrm{TiO}_{2}$ from MIL-125.[15] MIL-125 or CeBTC was placed in a ceramic crucible and calcined at $350{ }^{\circ} \mathrm{C}$ for 6 hours in air. The resulting oxide was recovered and stored in a desiccator until the materials were characterized.

TiO 2 Bulk. Bulk mixed-phase $\mathrm{TiO}_{2}$ was obtained from City Chemical (T7346-500GM) and used as received with no further purification or treatment.

$\mathrm{CeO}_{2}$ wires. The preparation of $\mathrm{CeO}_{2}$ wires has been described in detail elsewhere.[45] The morphology of $\mathrm{CeO}_{2}$ was controlled by varying the $\mathrm{pH}$, temperature and duration of the reaction. $\mathrm{Ce}\left(\mathrm{NO}_{3}\right)_{3} \cdot 6 \mathrm{H}_{2} \mathrm{O}$ and $\mathrm{NaOH}$ were used as precursors for $\mathrm{CeO}_{2}$ wires. The light yellow precipitate was centrifuged after the hydrothermal synthesis, and washed with deionized water and ethanol three times. The Na impurities were removed by baseacid wash, which was discussed in detail in previous work. The base-acid washed products were dried in vacuum overnight and then calcined at $400{ }^{\circ} \mathrm{C}$ in air for 4 hours.

Powder X-ray diffraction. Powder X-ray diffraction patterns were recorded on an X'Pert X-ray PANalytical diffractometer with an $\mathrm{X}^{\prime}$ accelerator module using $\mathrm{Cu} \mathrm{K \alpha}(\lambda=1.5418 \AA)$ radiation at room temperature, with a step size of $0.02^{\circ}$ in two theta $(2 \theta)$.

$\mathbf{N}_{2}$ physisorption. Nitrogen physisorption isotherms were measured at $77 \mathrm{~K}$ for samples activated at $473 \mathrm{~K}$ for $12 \mathrm{~h}$ under vacuum using the Quadrasorb system from Quantachrome instruments. Nitrogen adsorption analysis was performed on all resulting products, and surface areas for the MOFs were determined by applying BET theory over a range of data points applicable to microporous materials.[49] $\mathrm{N}_{2}$ isotherms showed typical Type I behavior as per the IUPAC classification.

In situ IR and Raman spectroscopy. The MOF-derived and oxide materials were pretreated at $300{ }^{\circ} \mathrm{C}$ at the rate of $10{ }^{\circ} \mathrm{C} / \mathrm{min}$ and held for $1 \mathrm{hr}$ in He flow at $50 \mathrm{~cm}^{3} / \mathrm{min}$. The MOF materials were activated ex situ under vacuum at $150{ }^{\circ} \mathrm{C}$ for MIL-125 and $250{ }^{\circ} \mathrm{C}$ for CeBTC. MIL-125 was pretreated at $150{ }^{\circ} \mathrm{C}$ to avoid degradation 
of the sample, and CeBTC was pretreated at $300{ }^{\circ} \mathrm{C}$ at the rate of $10{ }^{\circ} \mathrm{C} / \mathrm{min}$ and held for $1 \mathrm{hr}$ in $\mathrm{He}$ flow at 50 $\mathrm{cm}^{3} / \mathrm{min}$. The in situ spectroscopic studies consist of three cycles in succession on the same sample, two $\mathrm{CO}_{2}$ cycles, one before and one after an $\mathrm{SO}_{2}$ cycle. Each cycle consisted of the following steps (i) adsorption, (ii) He purge, and (iii) temperature programmed desorption (TPD). During the first step of the first and third cycles, $\mathrm{CO}_{2}$ adsorption, the material was exposed to $2 \% \mathrm{CO}_{2} / \mathrm{He}$ flow at $50 \mathrm{~cm}^{3} / \mathrm{min}$ for $15 \mathrm{~min}$ at $25{ }^{\circ} \mathrm{C}$. During the first step of the second cycle, $\mathrm{SO}_{2}$ adsorption, the material was exposed to $15 \mathrm{ppm} \mathrm{SO} / \mathrm{He}$ flow at $50 \mathrm{~cm}^{3} / \mathrm{min}$ for 15 min at $25{ }^{\circ} \mathrm{C}$. During the second step of each cycle, the He Purge, the residual gas was purged by He flow at $50 \mathrm{~cm}^{3} / \mathrm{min}$ for $10 \mathrm{~min}$ at $25{ }^{\circ} \mathrm{C}$. For the final step of each cycle temperature programmed desorption was performed, during which the material was heated to $300{ }^{\circ} \mathrm{C}$ at the rate of $10{ }^{\circ} \mathrm{C} / \mathrm{min}$; the temperature of the material was held at $300{ }^{\circ} \mathrm{C}$ for $30 \mathrm{~min}$, followed by cooling the material to $25{ }^{\circ} \mathrm{C}$ at the rate of $10{ }^{\circ} \mathrm{C} / \mathrm{min}$. For MIL-125 the temperature chosen for TPD matched that of its activation, $150{ }^{\circ} \mathrm{C}$, instead of $300{ }^{\circ} \mathrm{C}$ used for all other samples to prevent degradation of the material during heating.

IR spectra were collected continuously through the entire measurement cycle using a Thermo Nicolet Nexus 670 spectrometer in Diffuse Reflectance mode (DRIFTs), the outlet gases from the DRIFTs cell (Pike Technologies HC-900) were analyzed using a quadrupole mass spectrometer (Omnistar GSD-301 $\mathrm{O}_{2}$, Pfeiffer Vacuum). Absorbance spectra during $\mathrm{SO}_{2}$ adsorption were calculated as $A b s=-\log (I / I o)$, where $I$ is the single beam spectrum during adsorption and $I_{o}$ is the single beam spectrum before adsorption.

The Raman measurements were performed with a catalytic Raman reactor (Linkam CCR1000) using in-house built multiple-wavelengths Raman system[50] that includes laser excitations at $\lambda=325$ and $532 \mathrm{~nm}$. Raman scattering was collected using fiber optics connected directly to the spectrograph stage of the triple Raman spectrometer (Princeton Instruments Acton Trivista 555). Samples pretreatment and $\mathrm{SO}_{2}$ adsorption were carried out similarly as in the IR studies.

Scanning Electron Microscopy. Samples were imaged on a Zeiss Ultra60 FE-SEM instrument with a highefficiency in-lens SE detector at a working distance of 7-8 $\mathrm{mm}$ and accelerating voltage of $5 \mathrm{kV}$. The samples 
were sonicated for $10 \mathrm{~s}$ in methanol and then dispersed on a flat Al sample holder with two-sided adhesive conductive carbon tape. Prior to SEM observations, samples were coated with carbon for $30 \mathrm{~s}$ at $4.4 \mathrm{~V}$ using a Cressington 108A Carbon Coater to exclude the charging effect. Several images were captured for each sample with varying levels of magnifications.

Transmission Electron Microscopy. TEM images were obtained using a Hitachi HT7700 operated at $120 \mathrm{keV}$. The samples were deposited on a lacy carbon copper grid by suspending less than $1 \mathrm{mg}$ of material in methanol and dropcasting the suspension on the grid.

Water Vapor and $\mathrm{CO}_{2}$ Adsorption. A 3Flex Surface Characterization Analyzer from Micromeritics was used to collect water vapor isotherms at $22{ }^{\circ} \mathrm{C}$ for all samples. Isotherms were collected after in situ IR experiments with fresh, unexposed sample. Prior to water adsorption measurements, CeBTC was activated in a Smart VacPrep degasser at $300{ }^{\circ} \mathrm{C}$ for 12 hours under dynamic vacuum, MIL-125 was activated at $175{ }^{\circ} \mathrm{C}$ for 12 hours under dynamic vacuum, and all metal oxides were activated at $150{ }^{\circ} \mathrm{C}$ for 12 hours under dynamic vacuum. All water vapor isotherms were measured to $\mathrm{P} / \mathrm{P}_{0}=0.95$ to avoid water condensation.

$\mathrm{CO}_{2}$ isotherms were collected on MIL-125, $\mathrm{TiO}_{2}-\mathrm{d}$, and $\mathrm{CeBTC}$ on fresh sample as well as samples after in situ IR experiments. Prior to adsorption measurements, CeBTC was activated in a Smart VacPrep degasser at 300 ${ }^{\circ} \mathrm{C}$ for 12 hours under dynamic vacuum, MIL-125 was activated at $150{ }^{\circ} \mathrm{C}$ for 12 hours under dynamic vacuum, and $\mathrm{TiO}_{2}-\mathrm{d}$ was activated at $150{ }^{\circ} \mathrm{C}$ for 12 hours under dynamic vacuum. All isotherms were measured with $\mathrm{P}_{0}=$ $760 \mathrm{mmHg}$.

\section{RESULTS AND DISCUSSION}

\subsection{Characterization of pristine materials}

Powder X-ray diffraction (PXRD) was used to verify the structures of the MOFs and the oxides. Fig. A1 shows that the as-synthesized patterns for CeBTC and MIL-125 match the simulated patterns generated from 
literature.[51, 52] The MOF-derived $\mathrm{CeO}_{2}$, and $\mathrm{CeO}_{2}$ wires match the simulated ceria pattern (JCPDS Card No. 34-394), confirming the MOF-derived oxide possesses the same crystal structure as the $\mathrm{CeO}_{2}$ wires, albeit a different morphology. Derived $\mathrm{TiO}_{2}$ is synthesized in the anatase phase (JCPDS Card No. 21-1272), while the bulk $\mathrm{TiO}_{2}$ is present as a mixture of rutile (JCPDS Card No. 88-1175) and anatase phases. In addition, elemental analysis was performed on the derived oxide materials to verify that all carbonaceous material had been removed. Less than 0.5 wt.\% carbon remained for each sample, 0.44 for $\mathrm{CeO}_{2}$-d and 0.39 for $\mathrm{TiO}_{2}$-d, indicating complete removal of the organic linkers during preparation.

After confirming the crystalline structure of all materials, $\mathrm{N}_{2}$ physisorption was performed on each sample to determine the surface area and also elucidate the retained porosity of the MOF-derived oxides, which is a key feature of MOF-templated oxides in literature.[14] The MOF BET surface areas, shown in Table 1, were similar to those found in literature; $1392 \mathrm{~m}^{2} / \mathrm{g}$ for MIL-125 and $752 \mathrm{~m}^{2} / \mathrm{g}$ for CeBTC.[51, 52] After preparation through calcination of MIL-125, $\mathrm{TiO}_{2}$-d possesses mesopores with sizes ranging between 2-4 nm, while bulk $\mathrm{TiO}_{2}$ displays a distribution of micro, meso and macropores as seen in the pore size distribution shown in Fig. A2. The mesopores present in the $\mathrm{TiO}_{2}$ - $\mathrm{d}$ are the result of various degrees of connectivity arising during calcination between the $1.25 \mathrm{~nm}$ pores present in $\mathrm{MIL}-125 . \mathrm{CeO}_{2}$ - $\mathrm{d}$ shows a larger abundance of micropores than $\mathrm{CeO}_{2}$ wires, due to a degree of retained pore structure from the CeBTC parent material, though both show a distribution of macro, meso, and micropores. The $\mathrm{TiO}_{2}-\mathrm{d}$ and $\mathrm{CeO}_{2}-\mathrm{d}$ displayed markedly higher surface areas, 133 and $138 \mathrm{~m}^{2} / \mathrm{g}$, than the traditionally prepared oxides, 49 and $107 \mathrm{~m}^{2} / \mathrm{g}$, respectively. It is important to note that both of the MOF-derived oxides possess a large number of particle defects, such as cracks and voids, leading to an increase in surface area, which will be investigated further with SEM in a later section. These porous MOF-derived oxides will not only provide the basis for understanding acid gas adsorption on MOFs, but also insight into the effect of morphology and defects on material stability in MOFs and MOF-derived oxides. 


\subsection{Structure of $\mathrm{SO}_{x}$ species from $\mathrm{SO}_{2}$ adsorption}

Fig. 1 shows the IR spectra during $\mathrm{SO}_{2}$ adsorption on $\mathrm{CeBTC}, \mathrm{CeO}_{2}$-d, and $\mathrm{CeO}_{2}$ wires at room temperature as a function of time. $\mathrm{SO}_{2}$ adsorption on ceria is well-studied and the IR spectra shown in Fig. 1(c) for the $\mathrm{CeO}_{2}$ wires exhibits characteristic peaks at 1424, 1340, 1233, 1194, 1064, 1018, and $897 \mathrm{~cm}^{-1}$ indicating the formation of surface sulfates[20,21,37, 53-58] while peaks at 1018 and $989 \mathrm{~cm}^{-1}$ indicating the formation of surface sulfites $[59,60]$ during $\mathrm{SO}_{2}$ adsorption. The broad IR band at $1064 \mathrm{~cm}^{-1}$ appearing upon the start of $\mathrm{SO}_{2}$ adsorption also indicates the presence of surface sulfate species.[58] In addition, the spectra also exhibit characteristic negative peaks at 1398, 1289, and $1218 \mathrm{~cm}^{-1}$ indicating the perturbation of previously adsorbed surface carbonates [61-63] by adsorbed $\mathrm{SO}_{2}$. It is interesting to note that there is no increase in MS intensity to indicated $\mathrm{CO}_{2}$ evolving during $\mathrm{SO}_{2}$ adsorption, suggesting that few carbonates are displaced completely from the surface and rather the majority remain bound to the surface. This hypothesis is supported by the release of $\mathrm{CO}_{2}$ during $\mathrm{SO}_{2}$ TPD shown in Fig. A3, where these strongly bound species are not evolved until temperatures above $150{ }^{\circ} \mathrm{C}$, with a maximum intensity observed at $225^{\circ} \mathrm{C}$. These remnant carbonate species are likely explained by the high number of defects present in the material. To characterize the abundance of these defect sites, the ratio of the defects $\left(600 \mathrm{~cm}^{-1}\right)$ to the bulk $\left(465 \mathrm{~cm}^{-1}\right)$ in the Raman spectra shown in Fig. A4 was calculated in Table A1.[45] The ratio of defects to bulk for $\mathrm{CeO}_{2}$ wires drops $6.7 \%$ after exposure to $\mathrm{SO}_{2}$, suggesting the continued presence of $\mathrm{SO}_{\mathrm{x}}$ species occupying defect sites.

The preparation method for $\mathrm{CeO}_{2}$-d is hypothesized to produce a material that possesses a large number of defects in addition to the porosity retained from CeBTC. The defect ratio (see Table A1) calculated for freshly prepared $\mathrm{CeO}_{2}$-d from Raman spectrum is quite similar to that calculated for the $\mathrm{CeO}_{2}$ wires; however, after $\mathrm{SO}_{2}$ exposure the ratio drops $33.9 \%$, indicating a large loss of oxygen vacancies, likely due to a large number of $\mathrm{SO}_{\mathrm{x}}$ species occupying these sites. Comparison of the IR spectra on $\mathrm{CeO}_{2}$ wires with the spectra on $\mathrm{CeO}_{2}-\mathrm{d}$ shown in Fig. 1(b) shows a similar multitude of peaks at 1424, 1340, 1233, 1194, 1110, 898, and $849 \mathrm{~cm}^{-1}$ indicating the formation of surface sulfates, and the peak at $980 \mathrm{~cm}^{-1}$ indicating the formation of surface sulfites during $\mathrm{SO}_{2}$ adsorption.[20, 21, 37, 53-58, 64] The surface sulfate peaks at 1110 and $849 \mathrm{~cm}^{-1}$ are not observed 
for the $\mathrm{CeO}_{2}$ wires, and the $1110 \mathrm{~cm}^{-1}$ peak can be attributed to adsorption on an exposed (100) face as seen in our ongoing studies. In addition to these unique sulfate species, a difference is observed in the intensity of the negative peaks characteristic of the disturbed carbonates $\left(1398,1289\right.$, and $\left.1218 \mathrm{~cm}^{-1}\right)$; these features are much more intense for $\mathrm{CeO}_{2}$-d. The increase in intensity suggests the carbonate species are in higher abundance on $\mathrm{CeO}_{2}$-d than on $\mathrm{CeO}_{2}$ wires, which is supported by the higher intensity of $\mathrm{CO}_{2}$ observed during $\mathrm{SO}_{2} \mathrm{TPD}$ for $\mathrm{CeO}_{2}$-d shown in Fig. A3 and calculated in Table A2.

$\mathrm{SO}_{2}$ adsorption on CeBTC has not previously been investigated; however, the species observed over the $\mathrm{CeO}_{2}$-d allow the assignment of the species observed for the MOF. The IR spectra shown in Fig. 1(a) on CeBTC during $\mathrm{SO}_{2}$ adsorption exhibited a characteristic peak at $1166 \mathrm{~cm}^{-1}$ indicating the presence of physisorbed species, similar to that observed during $\mathrm{SO}_{2}$ adsorption over MOFs.[65] Peaks observed at 1027 and $983 \mathrm{~cm}^{-1} \mathrm{can} \mathrm{be}$ correlated with bands indicating the formation of similar surface sulfite species occurring at the location of oxygen vacancies seen on $\mathrm{CeO}_{2}$ wires. CeBTC possesses trivalent cerium atoms and the uncoordinated metal sites closely resemble cerium at sites with an oxygen vacancy; therefore, it can be determined that the formation of the observed sulfite species on CeBTC is occurring at the coordinatively-unsaturated metal sites. The peaks exhibited at 891 and $853 \mathrm{~cm}^{-1}$ mirror those seen on $\mathrm{CeO}_{2}-\mathrm{d}$ characteristic of the formation of surface sulfates species. The formation of these sulfates likely occurs between the oxygens connecting the tricarboxylate ligands and cerium atoms, as seen in other MOFs.[65] In addition, it is hypothesized that the observed sulfate species may form polynuclear species with the sulfites adsorbed on the open metal sites. No peaks characteristic of perturbation of adsorbed carbonates are observed on CeBTC during $\mathrm{SO}_{2}$ adsorption. In a study of co-adsorption of $\mathrm{CO}_{2}$ and $\mathrm{SO}_{2}$ on another open-metal site $\mathrm{MOF}$, Tan et al. discovered that the replacement of adsorbed $\mathrm{CO}_{2}$ by $\mathrm{SO}_{2}$ is slow,[66] which supports the lack of peaks characteristic of disturbed carbonates during the short time the sample is exposed to low concentration $\mathrm{SO}_{2}$. Monitoring of the $\mathrm{CO}_{2}$ evolved during $\mathrm{SO}_{2}$ TPD indicates a significant release of $\mathrm{CO}_{2}$ as the temperature rises above $250{ }^{\circ} \mathrm{C}$. A temperature of $300{ }^{\circ} \mathrm{C}$ has been identified as the necessary temperature to fully expose the open metal sites present in CeBTC;[48] therefore, these carbonate 
species remained adsorbed throughout the previous TPD and their bonds with the open metal sites have been slightly weakened by adsorbed $\mathrm{SO}_{2}$, allowing their displacement during $\mathrm{SO}_{2} \mathrm{TPD}$.

As expected, comparison of the amount and maximum desorption temperature of $\mathrm{SO}_{2}$ evolved during TPD (Fig. A5) for the three cerium containing samples reveals $\mathrm{CeBTC}$ adsorbs the largest amount of $\mathrm{SO}_{2}$ due to its high surface area, with continual release of physisorbed $\mathrm{SO}_{2}$ (indicated by the IR band at $1166 \mathrm{~cm}^{-1}$ ) beginning at 30 ${ }^{\circ} \mathrm{C}$. A peak in intensity is observed at $275{ }^{\circ} \mathrm{C}$ for $\mathrm{CeBTC}$, correlated with the previously mentioned temperature required during activation to remove adsorbed species from open metal sites. A similar peak at $280{ }^{\circ} \mathrm{C}$ has been observed on $\mathrm{CeO}_{2}$ rods in current work,[67] correlated with the release of sulfite species adsorbed at oxygen vacancies. Therefore, these similar peaks observed during TPD further support the hypothesis that the surface sulfite species observed at 1027 and $983 \mathrm{~cm}^{-1}$ for CeBTC occur at open metal sites mirroring the oxygen vacancies present in $\mathrm{CeO}_{2}$ wires. $\mathrm{CeO}_{2}$-d and $\mathrm{CeO}_{2}$ wires both exhibit a maximum in intensity at $65{ }^{\circ} \mathrm{C}$, with $\mathrm{CeO}_{2}$-d exhibiting a slightly higher amount of evolved $\mathrm{SO}_{2}$, as calculated in Table A2. The lack of a second maximum similar to that observed for CeBTC leads to the hypothesis that species remaining after the primary $\mathrm{CO}_{2}$ adsorption stage of the experiment occupy the most strongly adsorbing sites in the oxide materials, which is further supported by the release of $\mathrm{CO}_{2}$ at temperatures greater than $150{ }^{\circ} \mathrm{C}$ for both oxide materials, shown in Fig. A3.

Fig. 2 shows the IR spectra during $\mathrm{SO}_{2}$ adsorption on $\mathrm{MIL}-125, \mathrm{TiO}_{2}$-d, and $\mathrm{TiO}_{2}$ bulk at room temperature as a function of time. All samples exhibit weak interactions with $\mathrm{SO}_{2}$, in agreement with previous studies demonstrating $\mathrm{TiO}_{2}$ has weak interactions with $\mathrm{SO}_{2}$ in comparison to other metal oxides.[68] $\mathrm{TiO}_{2}-\mathrm{d}$ and $\mathrm{TiO}_{2}$ bulk exhibit an intense characteristic peak at $1628 \mathrm{~cm}^{-1}$, which, combined with a significant increase in intensity of the negative peak between $3800-3600 \mathrm{~cm}^{-1}$, indicates the reaction of $\mathrm{SO}_{2}$ with surface hydroxyl groups to form adsorbed $\mathrm{H}_{2} \mathrm{O}$.[42] Both $\mathrm{TiO}_{2}$ materials also exhibit characteristic peaks at 1380 and $1033 \mathrm{~cm}^{-1}$ indicating the formation of surface sulfate and sulfite species, respectively, on the anatase phase of titania.[56] In addition to these similar peaks, $\mathrm{TiO}_{2}-\mathrm{d}$ exhibits a peak at $1133 \mathrm{~cm}^{-1}$ also characteristic of adsorbed surface sulfite species on anatase titania.[56] This feature is lost in the background of the spectra of $\mathrm{TiO}_{2}$ bulk due to the mixture of 
anatase and rutile phases. While the IR spectra for both $\mathrm{TiO}_{2}$ samples resemble each other, an analysis of the $\mathrm{SO}_{2}$ TPD (Fig. A5) reveals a difference in the strength of adsorbed species. $\mathrm{TiO}_{2}$-d exhibits a slow release of $\mathrm{SO}_{2}$ reaching a maximum at $100{ }^{\circ} \mathrm{C}$, while $\mathrm{TiO}_{2}$ bulk reaches a maximum at $100{ }^{\circ} \mathrm{C}$ and a second maximum at $290{ }^{\circ} \mathrm{C}$, indicating strongly adsorbed $\mathrm{SO}_{2}$ species. The lack of this second increase in intensity in $\mathrm{TiO}_{2}-\mathrm{d}$ is explained by monitoring of $\mathrm{CO}_{2}$ evolved during $\mathrm{SO}_{2}$ TPD (Fig. A3). Only $\mathrm{TiO}_{2}$-d releases $\mathrm{CO}_{2}$ during $\mathrm{SO}_{2}$ TPD, with a large amount of $\mathrm{CO}_{2}$ released at $50{ }^{\circ} \mathrm{C}$, with smaller peaks observed at $220{ }^{\circ} \mathrm{C}$ and $290{ }^{\circ} \mathrm{C}$. Carbonate species present from the initial $\mathrm{CO}_{2}$ adsorption stage likely occupy the strongest adsorbing defect sites in the material, while physisorbed $\mathrm{CO}_{2}$ displaced by $\mathrm{SO}_{2}$ adsorption is trapped in the high porosity of the material until TPD is performed.

As with CeBTC, $\mathrm{SO}_{2}$ adsorption has not been studied on MIL-125; however, the knowledge of adsorbed species on $\mathrm{TiO}_{2}$-d allows for the assignment of the weak features observed on the metal-organic framework. The formation of surface sulfites, indicated by the characteristic peak at $1023 \mathrm{~cm}^{-1}$, likely occurs at the metal clusters where titanium-bridging oxygen atoms resemble the structure of anatase titania. The characteristic peak indicating an interaction of $\mathrm{SO}_{2}$ with surface hydroxyls to form adsorbed surface water, at $1628 \mathrm{~cm}^{-1}$, is also observed on MIL-125, a possible assignment given each titanium atom in the metal node possesses a hydroxyl group. However, the corresponding decrease in the region between $3800-3600 \mathrm{~cm}^{-1}$ is not observed. Instead, a steady increase in this region is observed during $\mathrm{SO}_{2}$ adsorption. This increase is explained by the presence of uncoordinated carboxylates as the material is degraded by reaction with $\mathrm{SO}_{2}$ leading to the evolution of bands corresponding to the hydroxyl $\left(3700-3600 \mathrm{~cm}^{-1}\right)$ and corresponding carbonyl groups $\left(1715 \mathrm{~cm}^{-1}\right)$ of the uncoordinated carboxylic acid linker. Furthermore, it is hypothesized that the formation of water by interaction of $\mathrm{SO}_{2}$ with the surface hydroxyls serves to further degrade the material and lead to a drastic loss of surface area, as shown in Table 1. 


\subsection{Effect of $\mathrm{SO}_{2}$ exposure on adsorbed species during $\mathrm{CO}_{2}$ adsorption}

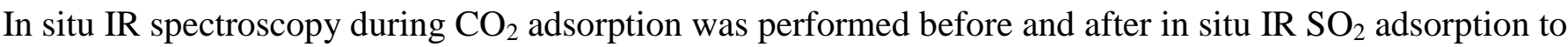
evaluate (i) the differences in adsorbed species between materials, and (ii) the effect of $\mathrm{SO}_{2}$ exposure on adsorbed $\mathrm{CO}_{2}$ species for each material. Fig. 3 shows the IR spectra during $\mathrm{CO}_{2}$ adsorption before and after in situ $\mathrm{SO}_{2}$ experiments on $\mathrm{CeBTC}, \mathrm{CeO}_{2}-\mathrm{d}$, and $\mathrm{CeO}_{2}$ wires at room temperature as a function of time. The IR spectra shown in Fig. 3(b) of $\mathrm{CeO}_{2}$-d during $\mathrm{CO}_{2}$ adsorption before $\mathrm{SO}_{2}$ adsorption exhibited peaks characteristic of bicarbonate, bridged carbonate, bidentate carbonate, and monodentate carbonate species summarized in Table 2.[61-63, 69-72] Ceria wires exhibited similar peaks; however, several peaks differed between the two samples. Notably, $\mathrm{CeO}_{2}-\mathrm{d}$ exhibits peaks characteristic of carbonate species at 1237, 1131, 997 $\mathrm{cm}^{-1},[63,72]$ while the $\mathrm{CeO}_{2}$ wires exhibit a peak characteristic of bidentate and monodentate carbonates at $1588 \mathrm{~cm}^{-1}$ not observed for $\mathrm{CeO}_{2}$-d.[61] The difference in observed species is likely due to the retained porosity of $\mathrm{CeO}_{2}$-d. This hypothesis is further supported by comparison of the IR spectra for both samples after $\mathrm{SO}_{2}$ experiments. The monodentate carbonate peak that is unique to the $\mathrm{CeO}_{2}$-d remains, but the unique bicarbonate species are no longer present on the $\mathrm{CeO}_{2}-\mathrm{d}$ sample, indicating the loss of these unique adsorption sites either through occupation by adsorbed sulfates or through degradation; a hypothesis supported by the $33.9 \%$ reduction in defect sites after $\mathrm{SO}_{2}$ exposure observed through Raman spectroscopy (Table A1). In addition, the IR spectra on $\mathrm{CeO}_{2}$-d very closely resembles the spectra on ceria wires after $\mathrm{SO}_{2}$ experiments, suggesting $\mathrm{CeO}_{2}-\mathrm{d}$ has transformed into a material possessing facets and defects very similar to those found on the ceria wires. Further investigation of this hypothesis with SEM and BET is discussed in the following section. The IR spectra shown in Fig. 3(a) of CeBTC during $\mathrm{CO}_{2}$ adsorption before $\mathrm{SO}_{2}$ adsorption exhibited characteristic peaks at 1165 , $1048,980 \mathrm{~cm}^{-1}$ similar to those observed on $\mathrm{CeO}_{2}$-d indicating the formation of bicarbonate and carbonate species during $\mathrm{CO}_{2}$ adsorption.[61] After exposure to $\mathrm{SO}_{2}, \mathrm{CeBTC}$ exhibits a single carbonate peak at $1123 \mathrm{~cm}^{-}$ ${ }^{1}$.[72] The loss of the peaks observed before $\mathrm{SO}_{2}$ exposure is correlated with the $100 \%$ loss of surface area, leaving only surface sites available for adsorption. 
Fig. 4 shows the IR spectra during $\mathrm{CO}_{2}$ adsorption on $\mathrm{MIL}-125, \mathrm{TiO}_{2}$-d, and $\mathrm{TiO}_{2}$ bulk at room temperature as a function of time both before and after the in situ IR $\mathrm{SO}_{2}$ experiment. The IR spectra on MIL-125 during $\mathrm{CO}_{2}$ adsorption exhibits no characteristic adsorption peaks due to the lack of open metal sites. $\mathrm{TiO}_{2}-\mathrm{d}$ and $\mathrm{TiO}_{2}$ bulk exhibit characteristic peaks at 1672 and $1429 \mathrm{~cm}^{-1}$ indicating the formation of mono- and bidentate bicarbonates, respectively, originating from the reaction of $\mathrm{CO}_{2}$ with residual hydroxyl groups.[23] In addition, $\mathrm{TiO}_{2}$-d exhibits peaks at 1221 and $1245 \mathrm{~cm}^{-1}$ indicative of monodentate bicarbonates and a peak at $1606 \mathrm{~cm}^{-1}$ that slowly shifts to $1635 \mathrm{~cm}^{-1}$ with increasing surface coverage indicative of bidentate bicarbonates not observed for the $\mathrm{TiO}_{2}$ bulk sample.[23] These species are likely more intense and able to be observed on $\mathrm{TiO}_{2}$-d due somewhat to the sample being pure anatase, but more importantly the presence of defects inherited through synthesis from the parent MIL-125. The $\mathrm{TiO}_{2}$ bulk sample also possesses a band at $1496 \mathrm{~cm}^{-1}$ characteristic of bidentate bicarbonates adsorbed on a rutile phase titania, $[73,74]$ demonstrating the mixed-phase titania results

in the formation of slightly different species than the pure phase $\mathrm{TiO}_{2}$-d. There is no loss of species observed for $\mathrm{TiO}_{2}$-d or $\mathrm{TiO}_{2}$ bulk after exposure to $\mathrm{SO}_{2}$; however, the intensity of the adsorbed species does decrease $31 \%$ and $14 \%$, respectively, after exposure, indicating a loss of adsorption sites after $\mathrm{SO}_{2}$ exposure. $\mathrm{TiO}_{2}$ - $\mathrm{d}$ possesses double the overall intensity of adsorption over $\mathrm{TiO}_{2}$ bulk, and experiences approximately double the decrease in intensity due to the loss of retained mesoporosity; a loss directly tied to the degradation of the MOF-like particles observed with SEM and discussed in the following section.

\subsection{Material stability after $\mathrm{SO}_{2}$ adsorption}

After in situ IR studies, the effect of acid gas exposure was first explored through PXRD analysis. As is known from literature, MOFs are often unstable upon exposure to certain gases and vapors, [10, 75] rapidly losing porosity and crystallinity. Comparison of the PXRD patterns taken before and after IR studies for MIL-125 and CeBTC (Fig. 5) reveals that both materials have not retained their crystallinity and no longer resemble the assynthesized patterns. The instability of these materials is further confirmed by comparing BET surface areas calculated from $\mathrm{N}_{2}$ physisorption before and after IR experiments. Both materials experience a drastic loss in 
surface area attributed to a degradation and loss of the material structure and porosity, $86 \%$ for MIL-125 and $100 \%$ for CeBTC, as shown in Table 1.

Analysis of the oxide materials; however, did not mimic the loss of stability observed for the MOF materials. Comparison of the PXRD patterns for all oxides revealed no change between the as-synthesized patterns and those taken before IR experiments. Although there was no observed change in the PXRD patterns after acid gas exposure, analysis of the materials' BET surface area revealed changes did occur for the MOF-derived oxide samples. The surface area of $\mathrm{CeO}_{2}$ wires and $\mathrm{TiO}_{2}$ bulk did not change after exposure; however, $\mathrm{CeO}_{2}$ - $\mathrm{d}$ and $\mathrm{TiO}_{2}$-d experience a loss in surface area of $10 \%$ and $65 \%$, respectively. The large loss in surface area without a corresponding change in the diffraction pattern indicates a loss of the retained porosity in the MOF-derived oxide particle, as illustrated in Fig. A2, reducing the surface area without greatly affecting the crystal structure.

In order to explore if a visual change to the particles could further confirm this hypothesis, SEM and TEM images were taken of all samples before and after in situ IR experiments. Fig. 6 shows the SEM images of titanium containing samples before and after in situ IR experiments, while Fig. A6-8 contains TEM images for these samples before and after in situ IR experiments. Fig. 6(a) and Fig. A6(a,d) show the characteristic terminated octahedral crystal of $\mathrm{MIL}-125 . \mathrm{TiO}_{2}-\mathrm{d}$ retains this overall particle structure in Fig. 6(b) and Fig. A7(a,d) as seen in literature.[14, 15] While the macroscopic particle morphology is retained, a loss of volume is observed upon preparation of the MOF-derived oxide, as expected. Fig. 6(c) and Fig. A8(a,d) show $\mathrm{TiO}_{2}$ bulk is composed of small agglomerates. Fig. 6(d-f) are SEM images of the titanium containing samples after in situ IR experiments. It can be observed from comparison of Fig. 6(c,f) that the $\mathrm{TiO}_{2}$ bulk sample does not undergo any change to the overall particle structure after acid gas exposure, further supporting the hypothesis that the $\mathrm{TiO}_{2}$ bulk is not degraded by exposure to $\mathrm{SO}_{2}$. Instead, the $22 \%$ reduction in $\mathrm{CO}_{2}$ capacity (calculated in Table A2) is likely due to retention of strongly bound $\mathrm{SO}_{\mathrm{x}}$ species even after desorption and TPD in He. A comparison of the images before and after exposure for MIL-125 yields the observation of the evolution of small agglomerates resembling the morphology of bulk $\mathrm{TiO}_{2}$ particles. In addition, close inspection of the SEM and TEM images reveals several instances of the creation of cavity defects in the MIL-125 crystal. These cavity defects are 
centered on the crystal edges where the surface is the most uncoordinated and allows for the strongest surface adsorption of acid gas molecules. The creation of these defects leads to an increase in uncoordinated sites where $\mathrm{SO}_{2}$ can strongly adsorb, allowing the degradation to propagate throughout the crystal. Furthermore, the degradation can be observed at different stages of progression in the image. In the upper right hand corner of Fig. 6(d), a crystal can be seen with a cavity defect that has begun at the corner of the particle and propagated along the face, while to the left, a particle is seen that has undergone much more degradation and has formed many more small agglomerates. This degradation and loss of material structure results in a loss in $\mathrm{CO}_{2}$ adsorption capacity as illustrated by the reduction in quantity adsorbed after IR experiments shown by the isotherms in Fig. A9. It is observed for $\mathrm{TiO}_{2}$-d that the retained particle structure has been lost upon exposure to acid gases as the sample is mainly comprised of the agglomerates seen in the bulk $\mathrm{TiO}_{2}$ sample. However, observation of one of the few remaining particles gives a glimpse into the degradation of the macroscopic particle and it is seen to be identical to the mechanism observed for a MIL-125 crystal. A small cavity defect has formed at the corner of the octahedral particle as well as a small agglomerate as the structured particle dissolves upon exposure. Additional SEM images shown in Fig. A10(a-e) illustrate the almost complete degradation of the $\mathrm{TiO}_{2}$-d particles to form small agglomerates after exposure to $\mathrm{SO}_{2}$ during in situ IR experiments. One important difference to note between the agglomerates observed in the MIL-125 sample after exposure and those in the $\mathrm{TiO}_{2}$ samples is that those observed in the MOF sample cannot yet be identified, while those in the $\mathrm{TiO}_{2}$-d are crystalline $\mathrm{TiO}_{2}$. Although visually similar, this difference is supported by the lack of evolution of any reflections characteristic of $\mathrm{TiO}_{2}$ in the PXRD pattern of MIL-125 after IR experiments. However, these reflections might be low in intensity and hidden by the still relatively intense reflections of degraded MIL-125.

SEM and TEM images of cerium containing samples before and after in situ IR experiments are shown in Fig. 7 and Fig. A11-13, respectively. Fig. 7(a) shows rod shaped crystals characteristic of CeBTC. The $\mathrm{CeO}_{2}$-d species is seen to retain this overall particle structure in Fig. 7(b), but as with $\mathrm{TiO}_{2}-\mathrm{d}$ the macroscopic particle structure is retained with a corresponding loss of volume. Fig. 7(c) shows the $\mathrm{CeO}_{2}$ wires, displaying characteristic small 
wire shaped particles. SEM images of the cerium containing samples after in situ IR experiments are shown in Fig. 7(d-f). As with the bulk $\mathrm{TiO}_{2}$, comparison of the $\mathrm{CeO}_{2}$ wires in Fig. 7(c,f) and in the TEM images in Fig. A13 shows that the sample does not undergo any change to the overall particle structure after acid gas exposure, supporting the hypothesis that the synthesized oxides are not degraded by exposure to $\mathrm{SO}_{2}$. Instead, the $10.9 \%$ reduction in $\mathrm{CO}_{2}$ adsorption capacity (Table A2) is likely due to retention of $\mathrm{SO}_{\mathrm{x}}$ species even after desorption and TPD in He. CeBTC particles after $\mathrm{SO}_{2}$ exposure in Fig. 7(d) resemble the overall morphology of the original material; however, the particles have agglomerated and have softened edges, suggesting a mechanism for degradation similar to MIL-125, where the most uncoordinated edge sites are attacked by $\mathrm{SO}_{2}$ during adsorption. Fig. A11(b,e) display the degradation of the CeBTC particle edges, with small fissures forming after $\mathrm{SO}_{2}$ exposure. $\mathrm{CeO}_{2}$-d particles, on the other hand, seem to retain a somewhat rod-like morphology even after acid gas exposure, and only a $2.3 \%$ reduction in $\mathrm{CO}_{2}$ capacity is observed (Table A2) with little to no change in the $\mathrm{CO}_{2}$ breakthrough time shown in Fig. A14. The retention of this morphology is probable given that rod shaped ceria has been synthesized previously.[61, 70] However, comparison of $\mathrm{CeO}_{2}$-d before and after experiment reveals the formation of cracks and fissures in the rod shaped particles and that some of the larger rod shaped particles have broken apart after exposure to form smaller rod shaped particles. This observation is explained by the high number of defects in the MOF-derived oxide allowing numerous sites for $\mathrm{SO}_{2}$ adsorption and the propagation of already existing cracks to break apart the larger rods and form smaller particles. It is important to note that the degradation of the samples is unlikely solely due to the TPD step during each segment of the experiment. The oxide materials showed less than $2 \mathrm{wt} \%$ loss during TGA as shown in Fig. A15. For the MOF materials, the chosen TPD temperature is well below the known upper stability limit, illustrated by a large wt. \% loss in Fig. A15. However, the addition of heat and the presence of adsorbed $\mathrm{SO}_{2}$ species likely hasten the degradation process. Additional studies are necessary to determine the kinetics of the degradation mechanism and how the addition of heat or additional acid gases will affect the speed of the degradation. 


\subsection{Effect of water adsorption on material stability}

Material stability and degradation in the presence of water vapor has been a widely explored topic within MOF literature.[75] Therefore, in order to explore similarities between degradation observed during acid gas exposure presented in the previous section and that observed during water exposure, each sample was characterized as above after water adsorption isotherms were collected. Water adsorption isotherms for cerium and titanium containing samples are shown in Fig. A16. As expected, the oxide materials do possess the high water adsorption observed for the MOF materials. The discrepancy in adsorbed amount is due to the high porosity of the MOF materials and the ability of water to cluster in the pores. Both MOF materials possess a virtually linear increase in adsorption as the relative water pressure is increased; however, MIL-125 desorbs the majority of the water adsorbed during the experiment while CeBTC possesses a much larger hysteresis and retains $17 \mathrm{mmol} / \mathrm{g}$ of water after desorption. As CeBTC possesses open metal sites, water is strongly adsorbed and will not desorb during evacuation without heating.

SEM and TEM images of both cerium and titanium containing samples after water adsorption experiments are shown in Fig. A17 and Fig. A6-12 (c,f), respectively. Fig. A17(a) and Fig. A11(c,f) show that the rod shaped crystals of CeBTC become softened after water adsorption; however, the change in morphology is not as drastic as observed after $\mathrm{SO}_{2}$ exposure. $\mathrm{N}_{2}$ physisorption and PXRD analysis after water adsorption revealed a drastic loss of surface area, 93\%, and a reduction in the intensity of reflections during diffraction experiments supporting the similar effects of water exposure and $\mathrm{SO}_{2}$ exposure for $\mathrm{CeBTC}$. The $\mathrm{CeO}_{2}$-d sample shown in Fig. A17(b) possesses numerous cracks and fissures in particles as well as a corresponding loss of surface area attributed to a loss of porosity after water exposure (Table 1); however, as with the CeBTC sample, the degree to which degradation has occurred is seemingly less than with $\mathrm{SO}_{2}$ as there is much less formation of smaller rod shaped particles. $\mathrm{CeO}_{2}$ wires continue to maintain their morphology after water exposure, confirming the particles are stable after water exposure due to their preparation via hydrothermal treatment. 
MIL-125 after water adsorption is shown in Fig. A17(d) and Fig. A6(c,f). The crystals do not display the

cavities seen in the sample after $\mathrm{SO}_{2}$ exposure, but instead a roughening and etching of the crystal surface is observed. This observation suggests that, similar to the CeBTC crystals, the degradation of the MIL-125 particles is proceeding at a much slower rate upon exposure to water over the day long isotherm run than that observed after 15 minutes of $15 \mathrm{ppm} \mathrm{SO}_{2}$ exposure. This hypothesis is further supported by PXRD and BET analysis, where some crystallinity is retained (Fig. A18, A19) and a less drastic loss of surface area is observed (Table 1). The $\mathrm{TiO}_{2}$-d species; however, does possess the cavities seen to evolve after exposure to $\mathrm{SO}_{2}$ as well as the corresponding decrease in surface area, 133 to $51 \mathrm{~m}^{2} / \mathrm{g}$, suggesting the degradation mechanism proceeds through the same pathway for both $\mathrm{SO}_{2}$ and $\mathrm{H}_{2} \mathrm{O}$ adsorption for the derived titania sample. Furthermore, the majority of $\mathrm{TiO}_{2}$-d has transformed from the octahedral shaped particles to the small agglomerates observed for the bulk $\mathrm{TiO}_{2}$. As was expected, the bulk $\mathrm{TiO}_{2}$ did not undergo any change in morphology, surface area, or diffraction pattern after water adsorption experiments.

\section{CONCLUSIONS}

In conclusion, we have investigated the effect of acid gas adsorption on a set of cerium and titanium MOFs, MOF-derived oxides, and oxides with IR spectroscopy, SEM, and TEM imaging. MOF-derived oxides were studied to create a link between the morphology of the parent MOF and the composition of the oxide, and gain insight into adsorbed species and possible degradation mechanisms. Adsorbed species on both parent MOFs could be directly correlated with observed adsorbed species on the MOF-derived oxide material. The retained porosity and inherent defects of $\mathrm{CeO}_{2}$-d changed the nature of species adsorbed, as well as enhanced the overall strength of adsorption of both $\mathrm{SO}_{2}$ and $\mathrm{CO}_{2}$. Although neither $\mathrm{TiO}_{2}$-d nor the bulk $\mathrm{TiO}_{2}$ strongly adsorbed $\mathrm{SO}_{\mathrm{x}}$ species, an increase in overall adsorption of the acid gases studied was observed for $\mathrm{TiO}_{2}-\mathrm{d}$, explained by the retained porosity during formation of the MOF-derived oxide. Insight into the degradation mechanism was developed through SEM and TEM imaging of samples before and after acid gas exposure. For MIL-125 and $\mathrm{TiO}_{2}$-d samples, exposure to $\mathrm{SO}_{2}$ or $\mathrm{H}_{2} \mathrm{O}$ resulted in the formation of cavity defects on the particle edge. It is hypothesized that the formation of these defects is due to the porous nature of the samples, the attack and 
degradation of the material begins at an uncoordinated edge and quickly propagates through the particle as the acid gas is able to penetrate into the particle. For $\mathrm{CeBTC}$ and $\mathrm{CeO}_{2}-\mathrm{d}$ samples, similar exposure resulted in a softening of particle edges, and for the MOF-derived oxide the breaking of particles into smaller particles along pre-existing cracks and fissures.

\section{ACKNOWLEDGMENTS}

The authors thank Karen Tulig for her help with TEM imaging. This work was supported as part of the Center for Understanding and Control of Acid Gas-Induced Evolution of Materials for Energy (UNCAGE-ME), an Energy Frontier Research Center funded by U.S. Department of Energy, Office of Science, Basic Energy Sciences under Award \#DE-SC0012577. Research at Oak Ridge National Laboratory, including the IR and Raman spectroscopy, was conducted at the Center for Nanophase Materials Sciences, which is a DOE Office of Science User Facility.

\section{REFERENCES}

[1] A.U. Czaja, N. Trukhan, U. Müller, Chem. Soc. Rev., 38 (2009) 1284-1293.

[2] J.R. Li, R.J. Kuppler, H.C. Zhou, Chem. Soc. Rev., 38 (2009) 1477-1504.

[3] S. Keskin, T.M. van Heest, D.S. Sholl, ChemSusChem, 3 (2010) 879-891.

[4] B. Yilmaz, N. Trukhan, U. Müller, Chinese J. Catal., 33 (2012) 3-10.

[5] K. Sumida, D.L. Rogow, J.A. Mason, T.M. McDonald, E.D. Bloch, Z.R. Herm, T.H. Bae, J.R. Long, Chem. Rev., 112 (2012) 724-781.

[6] A. Samanta, A. Zhao, G.K.H. Shimizu, P. Sarkar, R. Gupta, Ind. Eng. Chem. Res., 51 (2012) 14381463.

[7] S.T. Meek, J.A. Greathouse, M.D. Allendorf, Adv. Mater., 23 (2011) 249-267.

[8] J. Lee, O.K. Farha, J. Roberts, K.A. Scheidt, S.T. Nguyen, J.T. Hupp, Chem. Soc. Rev., 38 (2009) 14501459.

[9] F. Rezaei, A.A. Rownaghi, S. Monjezi, R.P. Lively, C.W. Jones, Energy Fuels, 29 (2015) 5467-5486.

[10] S.G. Han, Y.G. Huang, T. Watanabe, S. Nair, K.S. Walton, D.S. Sholl, J.C. Meredith, Microporous Mesoporous Mater., 173 (2013) 86-91. 
[11] P.K. Thallapally, R.K. Motkuri, C.A. Fernandez, B.P. McGrail, G.S. Behrooz, Inorg. Chem., 49 (2010) 4909-4915.

[12] J. Cui, Y.-L. Wong, M. Zeller, A.D. Hunter, Z. Xu, Angewandte Chemie International Edition, 53 (2014) 14438-14442.

[13] W. Chaikittisilp, N.L. Torad, C. Li, M. Imura, N. Suzuki, S. Ishihara, K. Ariga, Y. Yamauchi, Chem-Eur J, 20 (2014) 4217-4221.

[14] Z.Q. Wang, X. Li, H. Xu, Y. Yang, Y.J. Cui, H.G. Pan, Z.Y. Wang, B.L. Chen, G.D. Qian, J. Mater. Chem. A, 2 (2014) 12571-12575.

[15] J.H. Im, E. Kang, S.J. Yang, H.J. Park, J. Kim, C.R. Park, Bull. Korean Chem. Soc., 35 (2014) 24772480.

[16] D.D. Liu, F.N. Dai, X.H. Li, J.L. Liang, Y.Q. Liu, C.G. Liu, RSC Adv., 5 (2015) 15182-15186.

[17] K. Khaletskaya, A. Pougin, R. Medishetty, C. Rösler, C. Wiktor, J. Strunk, R.A. Fischer, Chem. Mater., (2015).

[18] D. Liu, F. Dai, H. Liu, Y. Liu, C. Liu, Mater. Lett., 139 (2015) 7-11.

[19] J.P. Dunn, J.-M. Jehng, D.S. Kim, L.E. Briand, H.G. Stenger, I.E. Wachs, J. Phys. Chem. B, 102 (1998) 6212-6218.

[20] T. Luo, R.J. Gorte, Appl. Catal., B, 53 (2004) 77-85.

[21] T. Luo, J.M. Vohs, R.J. Gorte, J. Catal., 210 (2002) 397-404.

[22] P. Bazin, O. Saur, J.C. Lavalley, G. Blanchard, V. Visciglio, O. Touret, Appl. Catal., B, 13 (1997) $265-$ 274.

[23] L. Mino, G. Spoto, A.M. Ferrari, J. Phys. Chem. C, 118 (2014) 25016-25026.

[24] M. Setvin, M. Buchholz, W. Hou, C. Zhang, B. Stöger, J. Hulva, T. Simschitz, X. Shi, J. Pavelec, G.S. Parkinson, M. Xu, Y. Wang, M. Schmid, C. Wöll, A. Selloni, U. Diebold, J. Phys. Chem. C, 119 (2015) 21044-21052.

[25] C. Orsenigo, L. Lietti, E. Tronconi, P. Forzatti, F. Bregani, Ind. Eng. Chem. Res., 37 (1998) 2350-2359.

[26] R. Flouty, E. Abi Aad, S. Siffert, A. Aboukais, A. Aboukaïs, J. Therm. Anal. Calorim., 73 (2003) $727-$ 734.

[27] J. Twu, C.J. Chuang, K.I. Chang, C.H. Yang, K.H. Chen, Appl. Catal., B, 12 (1997) 309-324.

[28] J. Rodriguez, T. Rodriguez, A. Jirsak, J. Freitag, J. Hanson, S. Larese, Chaturvedi, Catal. Lett., 62 (1999) 113-119.

[29] J. Kašpar, P. Fornasiero, M. Graziani, Catal. Today, 50 (1999) 285-298.

[30] R.J. Farrauto, R.M. Heck, Catal. Today, 51 (1999) 351-360.

[31] A. Trovarelli, C. de Leitenburg, M. Boaro, G. Dolcetti, Catal. Today, 50 (1999) 353-367.

[32] J. Kašpar, P. Fornasiero, N. Hickey, Catal. Today, 77 (2003) 419-449.

[33] S. Hilaire, S. Sharma, R.J. Gorte, J.M. Vohs, H.W. Jen, Catal. Lett., 70 (2000) 131-135.

[34] T. Kolli, M. Huuhtanen, A. Hallikainen, K. Kallinen, R.L. Keiski, Catal. Lett., 127 (2009) 49-54.

[35] Y. Wang, X. Li, L. Zhan, C. Li, W. Qiao, L. Ling, Ind. Eng. Chem. Res., 54 (2015) 2274-2278.

[36] E. Park, M. Kim, H. Jung, S. Chin, J. Jurng, ACS Catal., 3 (2013) 1518-1525.

[37] J. Liu, X.Y. Li, Q.D. Zhao, C. Hao, S.B. Wang, M. Tade, ACS Catal., 4 (2014) 2426-2436.

[38] A. Fujishima, K. Honda, Nature, 238 (1972) 37-38.

[39] A.L. Linsebigler, G. Lu, J.T. Yates, Chem. Rev., 95 (1995) 735-758.

[40] X. Zhang, Z. Pei, X. Ning, H. Lu, H. Huang, RSC Adv., 5 (2015) $79192-79199$.

[41] T.L. Thompson, J.T. Yates, Chem. Rev., 106 (2006) 4428-4453.

[42] W. Xu, H. He, Y. Yu, J. Phys. Chem. C, 113 (2009) 4426-4432.

[43] B.Q. Jiang, Z.B. Wu, Y. Liu, S.C. Lee, W.K. Ho, J. Phys. Chem. C, 114 (2010) 4961-4965.

[44] F. Notoya, C. Su, E. Sasaoka, S. Nojima, Ind. Eng. Chem. Res., 40 (2001) 3732-3739.

[45] Z. Wu, M. Li, J. Howe, H.M. Meyer, S.H. Overbury, Langmuir, 26 (2010) 16595-16606.

[46] J.H. Im, N. Ko, S.J. Yang, H.J. Park, J. Kim, C.R. Park, New J. Chem., 38 (2014) 2752-2755.

[47] S. Vaesen, V. Guillerm, Q. Yang, A.D. Wiersum, B. Marszalek, B. Gil, A. Vimont, M. Daturi, T. Devic, P.L. Llewellyn, C. Serre, G. Maurin, G. De Weireld, Chem. Commun., 49 (2013) 10082-10084.

[48] W. Mu, X. Huang, R. Zhong, W. Xia, J. Liu, R. Zou, CrystEngComm, 17 (2015) 1637-1645.

[49] K.S. Walton, R.Q. Snurr, J. Am. Chem. Soc., 129 (2007) 8552-8556. 
[50] Z. Wu, S. Dai, S.H. Overbury, J. Phys. Chem. C, 114 (2010) 412-422.

[51] M. Gustafsson, A. Bartoszewicz, B. Martín-Matute, J. Sun, J. Grins, T. Zhao, Z. Li, G. Zhu, X. Zou, Chem. Mater., 22 (2010) 3316-3322.

[52] M. Dan-Hardi, C. Serre, T. Frot, L. Rozes, G. Maurin, C. Sanchez, G. Férey, J. Am. Chem. Soc., 131 (2009) 10857-10859.

[53] F.A. Cotton, G. Wilkinson, M. Bochmann, C.A. Murillo, Advanced Inorganic Chemistry, Wiley1999.

[54] M. Waqif, P. Bazin, O. Saur, J.C. Lavalley, G. Blanchard, O. Touret, Appl. Catal., B, 11 (1997) 193205.

[55] B.A. Morrow, R.A. McFarlane, M. Lion, J.C. Lavalley, J. Catal., 107 (1987) 232-239.

[56] O. Saur, M. Bensitel, A.B.M. Saad, J.C. Lavalley, C.P. Tripp, B.A. Morrow, J. Catal., 99 (1986) 104110 .

[57] C. Morterra, G. Cerrato, V. Bolis, Catal. Today, 17 (1993) 505-515.

[58] C. Morterra, G. Cerrato, C. Emanuel, V. Bolis, J. Catal., 142 (1993) 349-367.

[59] N.B. Colthup, L.H. Daly, S.E. Wiberley, Introduction to Infrared and Raman Spectroscopy, Elsevier Science1990.

[60] J.C. Lavalley, Catal. Today, 27 (1996) 377-401.

[61] Z. Wu, A.K.P. Mann, M. Li, S.H. Overbury, J. Phys. Chem. C, 119 (2015) 7340-7350.

[62] C. Binet, M. Daturi, J.-C. Lavalley, Catal. Today, 50 (1999) 207-225.

[63] G.N. Vayssilov, M. Mihaylov, P.S. Petkov, K.I. Hadjiivanov, K.M. Neyman, J. Phys. Chem. C, 115 (2011) 23435-23454.

[64] Z. Lu, C. Müller, Z. Yang, K. Hermansson, J. Kullgren, J. Chem. Phys., 134 (2011) 184703.

[65] K. Tan, P. Canepa, Q. Gong, J. Liu, D.H. Johnson, A. Dyevoich, P.K. Thallapally, T. Thonhauser, J. Li, Y.J. Chabal, Chem. Mater., 25 (2013) 4653-4662.

[66] K. Tan, S. Zuluaga, Q. Gong, Y. Gao, N. Nijem, J. Li, T. Thonhauser, Y.J. Chabal, Chem. Mater., 27 (2015) 2203-2217.

[67] U. Tumuluri, M. Li, B. Cook, B.G. Sumpter, S. Dai, Z. Wu, The Journal of Physical Chemistry C, (2015).

[68] M. Ziolek, J. Kujawa, O. Saur, A. Aboulayt, J.C. Lavalley, J. Mol. Catal. A: Chem., 112 (1996) 125132.

[69] G. Finos, S. Collins, G. Blanco, E. del Rio, J.M. Cíes, S. Bernal, A. Bonivardi, Catal. Today, 180 (2012) 9-18.

[70] Z. Wu, M. Li, S.H. Overbury, J. Catal., 285 (2012) 61-73.

[71] C. Li, Y. Sakata, T. Arai, K. Domen, K.-i. Maruya, T. Onishi, J. Chem. Soc., Faraday Trans., 85 (1989) 1451-1461.

[72] C. Li, Y. Sakata, T. Arai, K. Domen, K.-i. Maruya, T. Onishi, J. Chem. Soc., Faraday Trans., 85 (1989) 929-943.

[73] P. Jackson, G.D. Parfitt, J. Chem. Soc., Faraday Trans., 68 (1972) 896-906.

[74] L.F. Liao, C.F. Lien, D.L. Shieh, M.T. Chen, J.L. Lin, J. Phys. Chem. B, 106 (2002) 11240-11245.

[75] N.C. Burtch, H. Jasuja, K.S. Walton, Chem. Rev., 114 (2014) 10575-10612. 
Table 1. BET surface areas for samples as-synthesized, after in situ IR experiments (Post IR), and after water adsorption experiments (Post $\left.\mathrm{H}_{2} \mathrm{O}\right)$.

\begin{tabular}{cccc} 
Material & $\mathrm{SA}_{\mathrm{BET}}(\mathrm{m} 2 / \mathrm{g})$ & $\begin{array}{c}\mathrm{SA}_{\mathrm{BET}}\left(\mathrm{m}^{2} / \mathrm{g}\right) \\
\text { Post IR }\end{array}$ & $\begin{array}{c}\mathrm{SA}_{\mathrm{BET}}\left(\mathrm{m}^{2} / \mathrm{g}\right) \\
\text { Post } \mathrm{H}_{2} \mathrm{O}\end{array}$ \\
\hline $\mathrm{CeBTC}$ & 752 & 0 & 52 \\
$\mathrm{CeO}_{2}$-d & 138 & 124 & 117 \\
$\mathrm{CeO}_{2}$ wires & 107 & 104 & 108 \\
$\mathrm{MIL}^{2}$ 125(Ti) & 1392 & 190 & 398 \\
$\mathrm{TiO}_{2}$-d & 133 & 47 & 51 \\
$\mathrm{TiO}_{2}$ bulk & 49 & 54 & 47
\end{tabular}


Table 2: Assignment of IR bands observed upon room temperature $\mathrm{CO}_{2}$ and $\mathrm{SO}_{2}$ adsorption on cerium and titanium containing samples.

\begin{tabular}{ll} 
Species & Band Assignment \\
\hline sulfates & $1424,1380,1340,1233,1194,1133,1110,1064,10331018,897,849$ \\
sulfites & $1133,1018,989$ \\
physisorbed $\mathrm{SO}_{2}$ & 1166 \\
& \\
Species & Band Assignment \\
\hline bicarbonates & $1674,1606,1496,1429,1245,1221,1215,1025,980$ \\
carbonates & $1588,1402,1284,1237,1165,1131,1025,997$
\end{tabular}



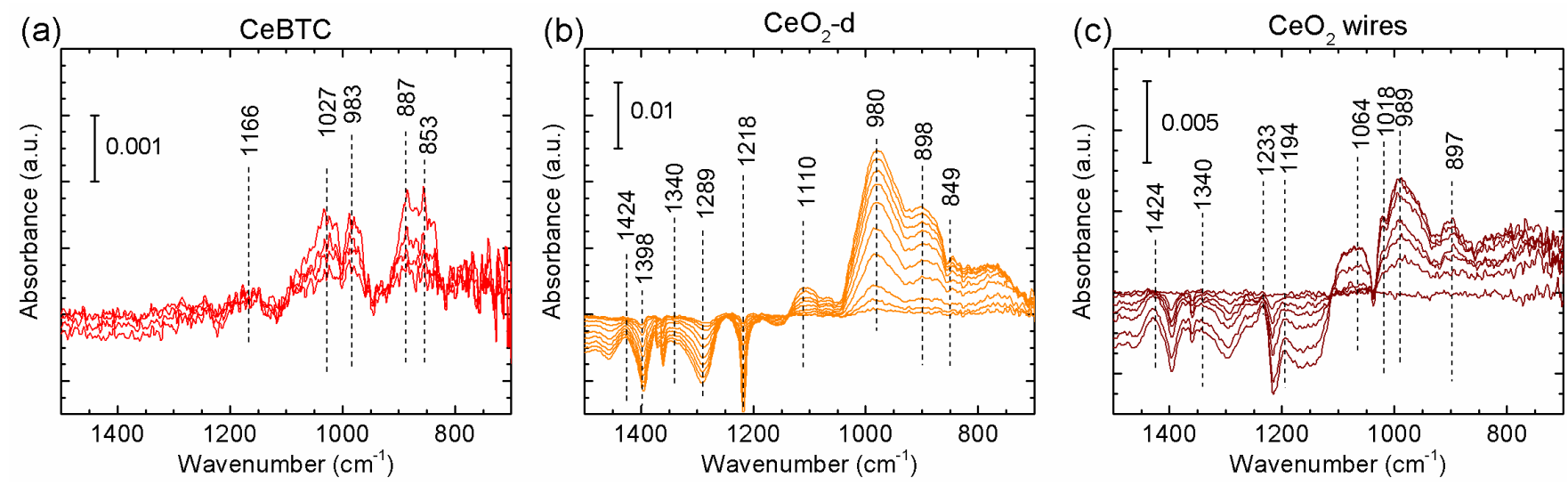

Fig. 1. IR spectra during 15 minutes of $\mathrm{SO}_{2}$ adsorption on $\mathrm{CeBTC}, \mathrm{CeO}_{2}-\mathrm{d}$, and $\mathrm{CeO}_{2}$ wires at $25^{\circ} \mathrm{C}$. 



Fig. 2. IR spectra during 15 minutes of $\mathrm{SO}_{2}$ adsorption on $\mathrm{MIL}-125, \mathrm{TiO}_{2}$-d, and $\mathrm{TiO}_{2}$ bulk at $25{ }^{\circ} \mathrm{C}$. 

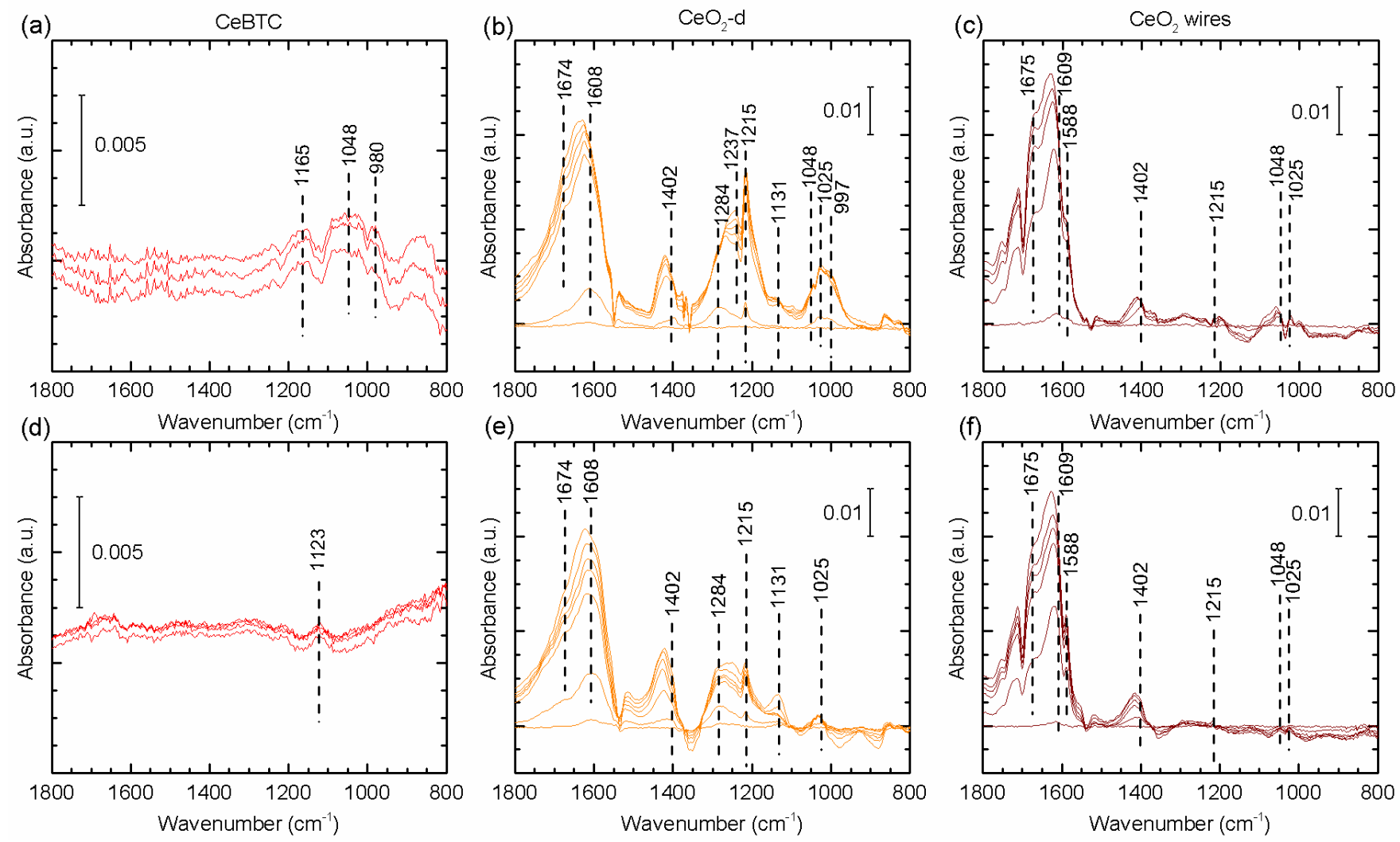

Fig. 3. IR spectra during 15 minutes of $\mathrm{CO}_{2}$ adsorption on (a,d) $\mathrm{CeBTC}$, (b,e) $\mathrm{CeO}_{2}$-d, and (c,f) $\mathrm{CeO}_{2}$ wires on pristine sample (a-c) and after in situ $\mathrm{SO}_{2}$ exposure (d-f) at $25^{\circ} \mathrm{C}$. 

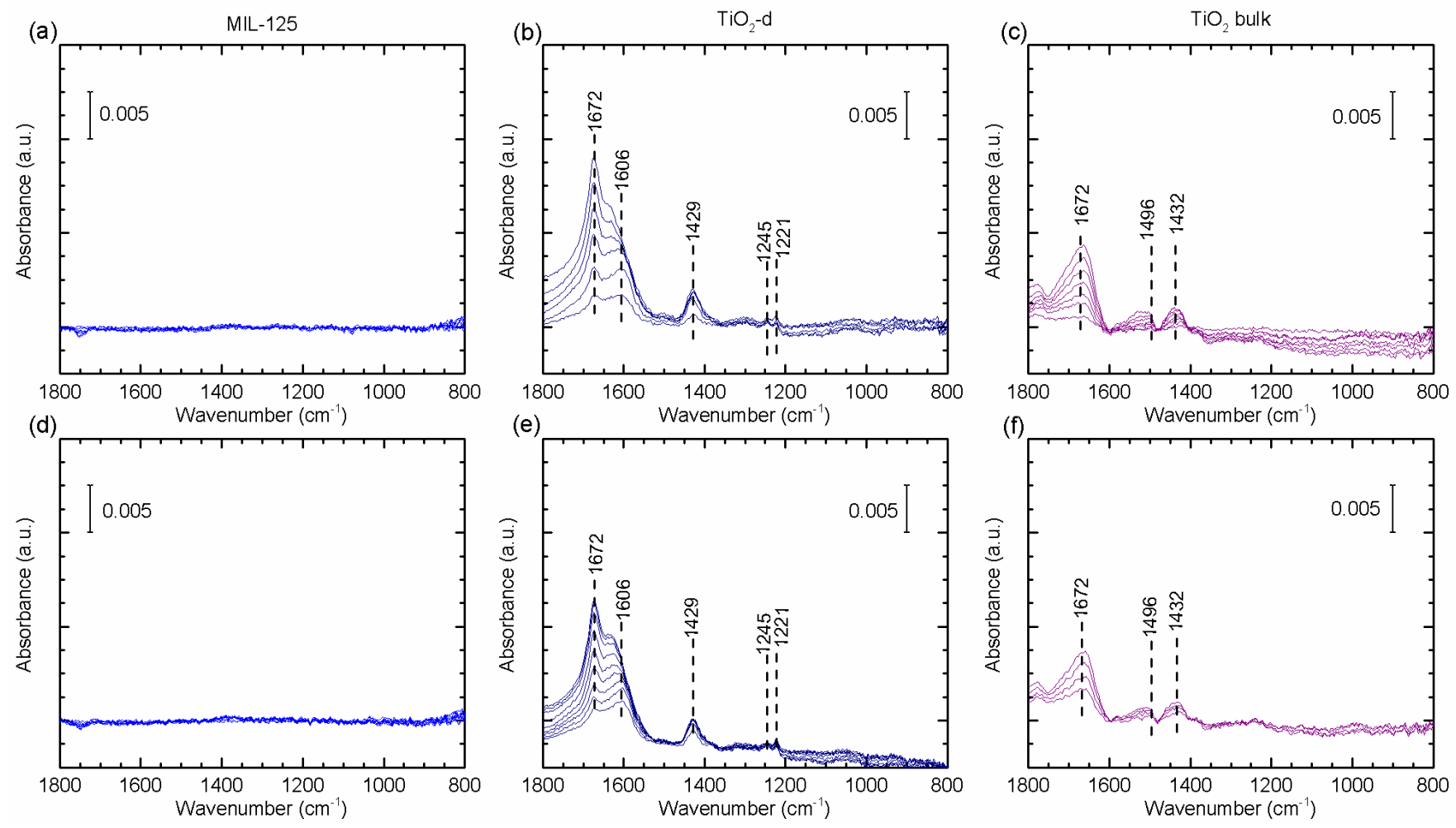

Fig. 4. IR spectra during different time intervals of $\mathrm{CO}_{2}$ adsorption on MIL-125, $\mathrm{TiO}_{2}$-d, and $\mathrm{TiO}_{2}$ bulk on pristine sample (top) and after in situ $\mathrm{SO}_{2}$ exposure (bottom) at $25^{\circ} \mathrm{C}$. 



Fig. 5. PXRD patterns of (top) $\mathrm{CeBTC}$ as-synthesized, $\mathrm{CeBTC}$ after $\mathrm{SO}_{2}$ exposure, $\mathrm{CeO}_{2}-\mathrm{d}$ as-synthesized, $\mathrm{CeO}_{2}$-d after $\mathrm{SO}_{2}$ exposure, $\mathrm{CeO}_{2}$ wire as-synthesized, $\mathrm{CeO}_{2}$ wires after $\mathrm{SO}_{2}$ exposure, and (bottom) MIL-125 as-synthesized, MIL-125 after $\mathrm{SO}_{2}$ exposure, $\mathrm{TiO}_{2}$-d as-synthesized, $\mathrm{TiO}_{2}$-d after $\mathrm{SO}_{2}$ exposure, $\mathrm{TiO}_{2}$ bulk, $\mathrm{TiO}_{2}$ bulk after $\mathrm{SO}_{2}$ exposure. 


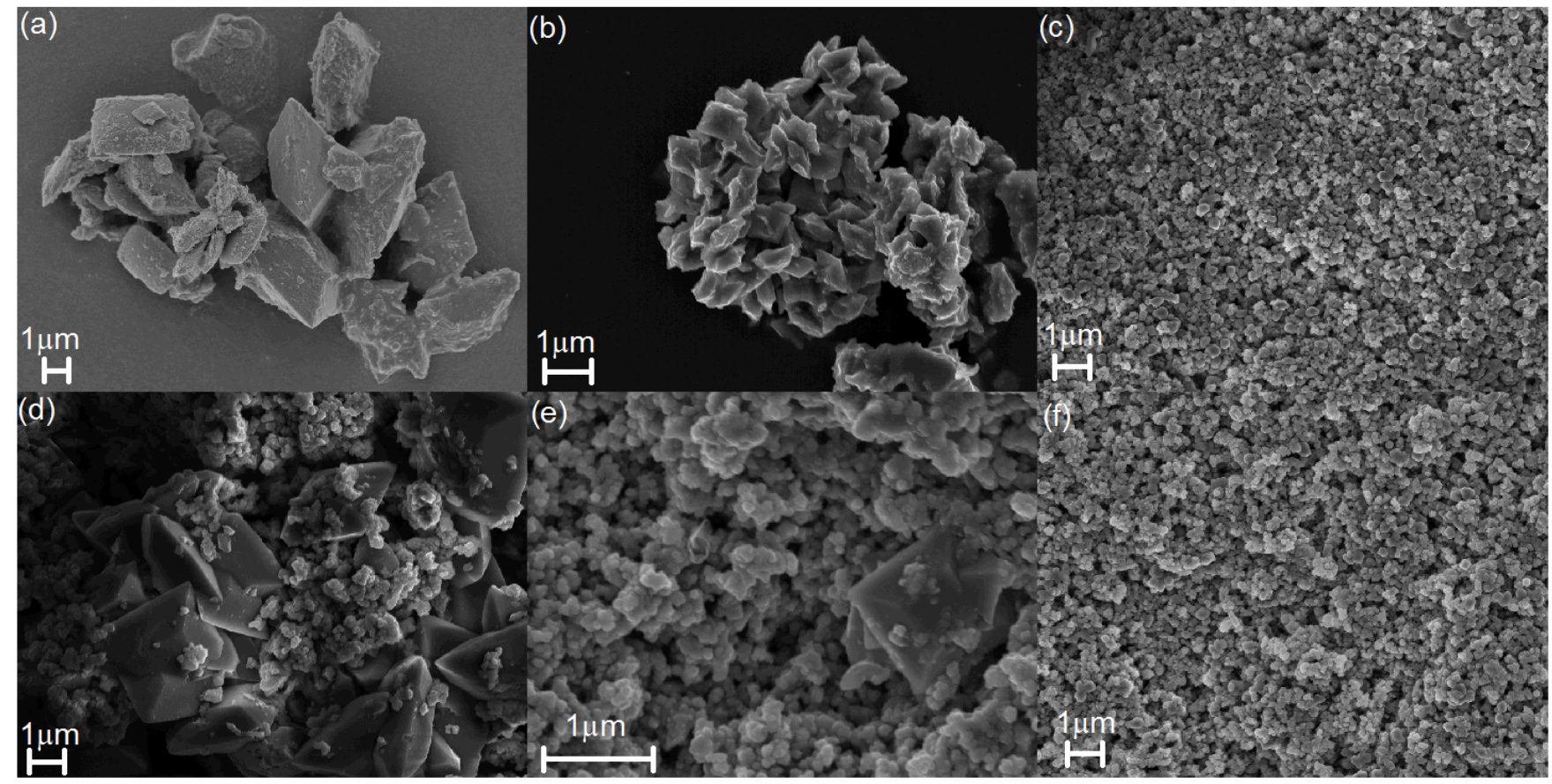

Fig. 6. SEM images of (a) MIL-125, (b) $\mathrm{TiO}_{2}$-d, (c) $\mathrm{TiO}_{2}$ bulk before IR experiments, and (d) MIL-125, (e) $\mathrm{TiO}_{2}$-d, (f) $\mathrm{TiO}_{2}$ bulk after IR experiments. 


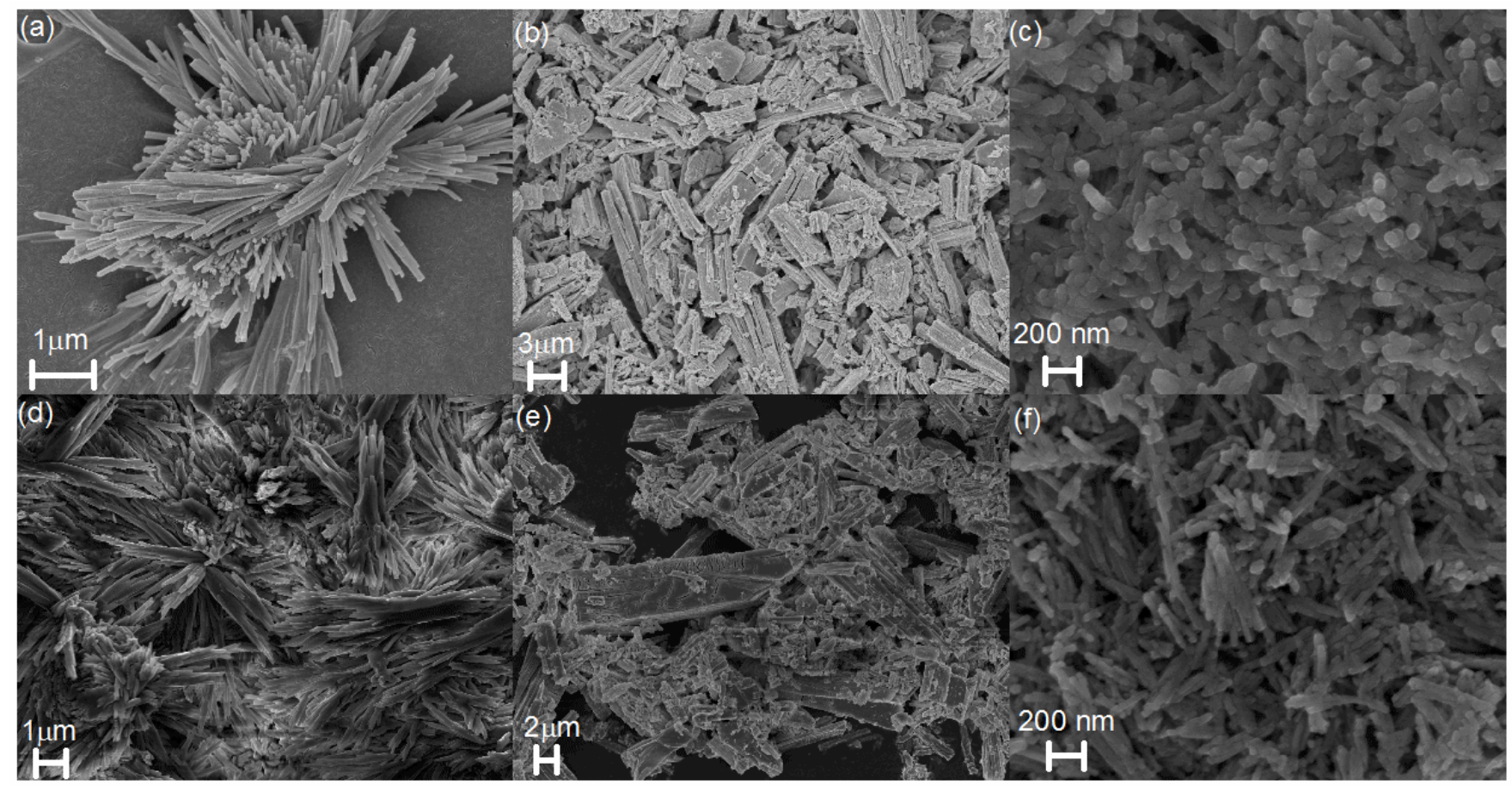

Fig. 7. $\mathrm{SEM}$ images of (a) $\mathrm{CeBTC}$, (b) $\mathrm{CeO}_{2}-\mathrm{d}$, (c) $\mathrm{CeO}_{2}$ wires before IR experiments, and (d) $\mathrm{CeBTC}$, (e) $\mathrm{CeO}_{2}-\mathrm{d}$, (f) $\mathrm{CeO}_{2}$ wires after IR experiments. 
Graphical Abstract
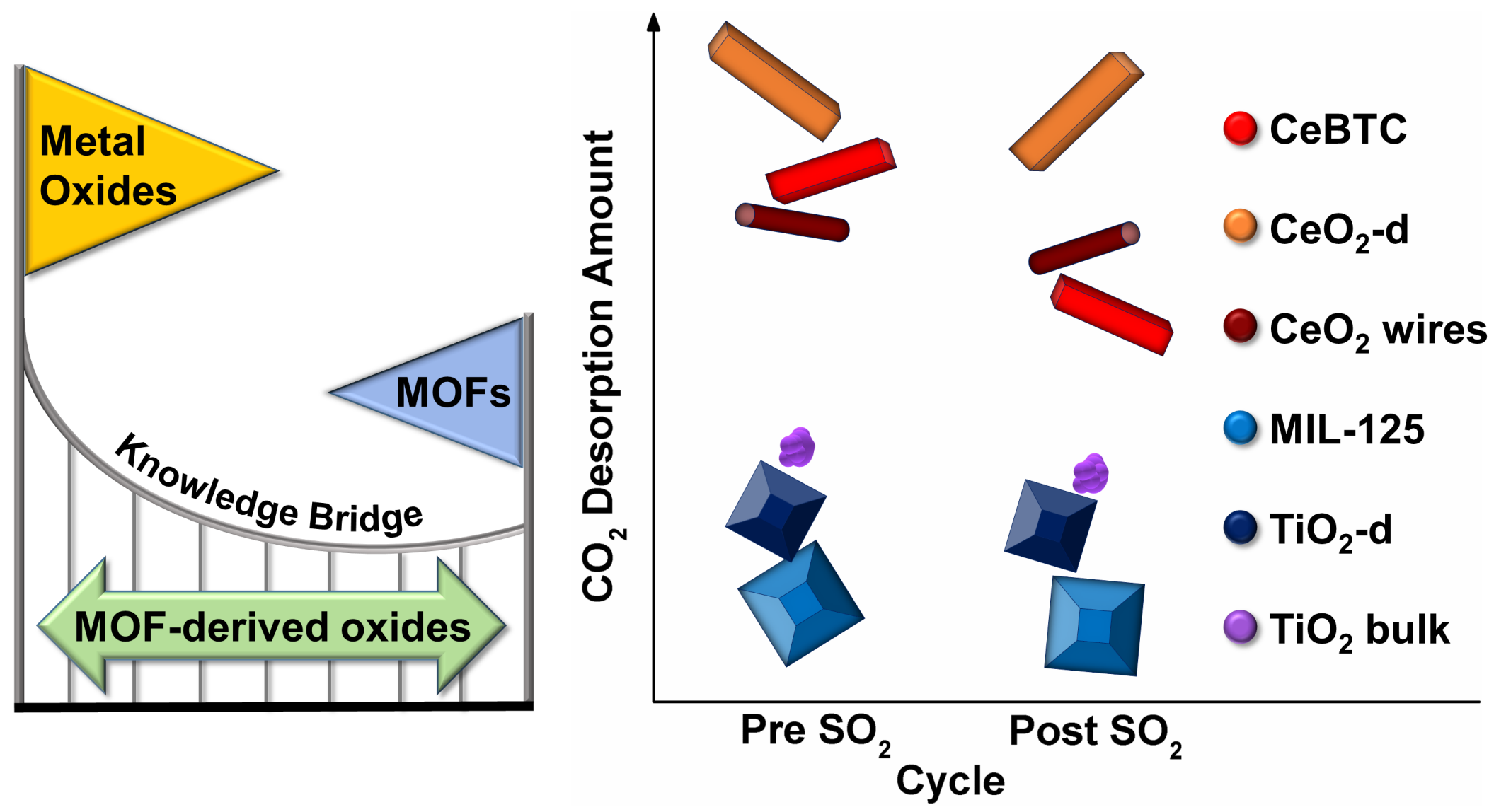